Jingwen Ran*, Jun Pei and Zhiwei Du

\title{
The crystal structure of poly[bis $\left(\mu_{4}-2,3-\right.$ pyridinedicarboxylato)-( $\mu_{2}$-oxalyl dihydrazide)- dicadmium(II) dihydrate], $\mathrm{C}_{16} \mathrm{H}_{16} \mathrm{O}_{12} \mathrm{~N}_{6} \mathrm{Cd}_{2}$
}

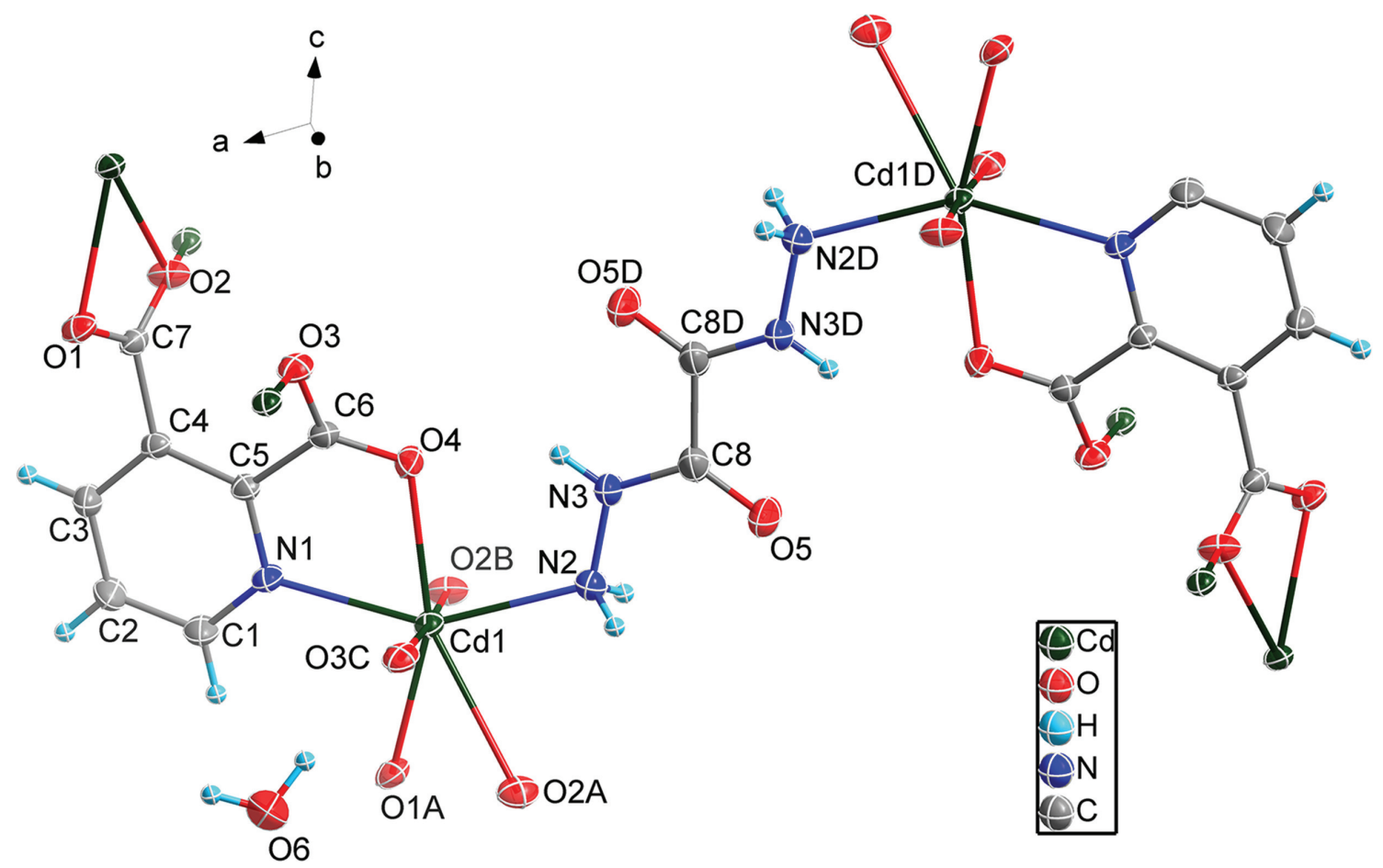

https://doi.org/10.1515/ncrs-2020-0180

Received April 11, 2020; accepted May 11, 2020; available online June 9, 2020

\section{Abstract}

$\mathrm{C}_{16} \mathrm{H}_{16} \mathrm{O}_{12} \mathrm{~N}_{6} \mathrm{Cd}_{2}$, monoclinic, $P 21 / n$ (no. 14), $a=$ 9.9709(2) $\AA, b=7.1597(2) \AA, c=15.4572(4) \AA, \beta=108.401(1)^{\circ}$, $V=1047.05(5) \AA^{3}, Z=4, R_{\mathrm{gt}}(F)=0.0168, w R_{\mathrm{ref}}\left(F^{2}\right)=0.0401$, $T=297(2) \mathrm{K}$.

CCDC no.: 2003209

*Corresponding author: Jingwen Ran, Hubei Key Laboratory for Processing and Application of Catalytic Materials, College of Chemistry and Chemical Engineering, Huanggang Normal University, Huanggang 438000, China, e-mail: ranjingwen@hgnu.edu.cn. https://orcid.org/0000-00018701-6192

Jun Pei and Zhiwei Du: Wuhan Blue Sky and Green Field Consulting Design Co., Ltd, Wuhan 430000, China
Table 1: Data collection and handling.

\section{Crystal:}

Size:

Wavelength:

$\mu$ :

Diffractometer, scan mode:

$\theta_{\max }$, completeness:

$N(h k l)_{\text {measured }}, N(h k l)_{\text {unique }}, R_{\text {int }}$ : Criterion for $I_{\mathrm{obs}}, N\left(h k l_{\mathrm{gt}}\right.$ : $N(\text { param })_{\text {refined: }}$ Programs:
Colorless cubic

$0.35 \times 0.33 \times 0.32 \mathrm{~mm}$

Mo $K \alpha$ radiation $(0.71073 \AA)$

$2.11 \mathrm{~mm}^{-1}$

Bruker Smart Apex, $\omega$

$28.3^{\circ},>99 \%$

10466, 2602, 0.019

$I_{\text {obs }}>2 \sigma\left(I_{\text {obs }}\right), 2425$

172

Bruker [1], SHELX [2, 3], Diamond [4]
A part of the molecular structure is shown in the figure. Table 1 contains crystallographic data and Table 2 contains the list of the atoms including atomic coordinates and displacement parameters. 
Table 2: Fractional atomic coordinates and isotropic or equivalent isotropic displacement parameters $\left(\AA^{2}\right)$.

\begin{tabular}{lrrrr}
\hline Atom & $\boldsymbol{x}$ & $\boldsymbol{y}$ & $\boldsymbol{Z}$ & $\boldsymbol{U}_{\text {iso }} \boldsymbol{U}_{\text {eq }}$ \\
\hline Cd1 & $0.34499(2)$ & $0.33271(2)$ & $0.34110(2)$ & $0.01856(5)$ \\
O1 & $0.87783(14)$ & $0.20557(19)$ & $0.70165(9)$ & $0.0235(3)$ \\
O2 & $0.72062(15)$ & $-0.01774(19)$ & $0.68764(9)$ & $0.0260(3)$ \\
O3 & $0.57370(14)$ & $0.35372(18)$ & $0.62792(8)$ & $0.0221(3)$ \\
O4 & $0.39136(14)$ & $0.3240(2)$ & $0.50042(9)$ & $0.0249(3)$ \\
O5 & $-0.10751(17)$ & $0.5614(3)$ & $0.39011(11)$ & $0.0429(4)$ \\
O6 & $0.6068(2)$ & $0.6544(3)$ & $0.26489(13)$ & $0.0521(5)$ \\
H6A & $0.6907(18)$ & $0.645(5)$ & $0.294(2)$ & $0.078^{*}$ \\
H6B & $0.555(3)$ & $0.639(5)$ & $0.299(2)$ & $0.078^{*}$ \\
N1 & $0.57286(16)$ & $0.2178(2)$ & $0.41000(10)$ & $0.0211(3)$ \\
H11 & $0.179(3)$ & $0.393(3)$ & $0.4777(16)$ & $0.025^{*}$ \\
N2 & $0.12079(17)$ & $0.4092(2)$ & $0.34702(10)$ & $0.0223(3)$ \\
H21 & 0.0961 & 0.5190 & 0.3197 & $0.027^{*}$ \\
H22 & 0.0598 & 0.3246 & 0.3149 & $0.027^{*}$ \\
N3 & $0.10636(18)$ & $0.4198(3)$ & $0.43536(11)$ & $0.0244(3)$ \\
C1 & $0.6554(2)$ & $0.1442(3)$ & $0.36565(13)$ & $0.0278(4)$ \\
H1A & 0.6272 & 0.1531 & 0.3024 & $0.033^{*}$ \\
C2 & $0.7819(2)$ & $0.0549(3)$ & $0.41056(13)$ & $0.0302(5)$ \\
H2 & 0.8375 & 0.0045 & 0.3781 & $0.036^{*}$ \\
C3 & $0.8235(2)$ & $0.0425(3)$ & $0.50436(13)$ & $0.0247(4)$ \\
H3A & 0.9075 & -0.0172 & 0.5358 & $0.030^{*}$ \\
C4 & $0.73951(18)$ & $0.1195(2)$ & $0.55162(11)$ & $0.0167(3)$ \\
C5 & $0.61425(18)$ & $0.2071(2)$ & $0.50176(11)$ & $0.0166(3)$ \\
C6 & $0.51767(19)$ & $0.3016(2)$ & $0.54692(12)$ & $0.0170(3)$ \\
C7 & $0.78129(18)$ & $0.1009(3)$ & $0.65391(11)$ & $0.0173(3)$ \\
C8 & $-0.0055(2)$ & $0.4987(3)$ & $0.44935(13)$ & $0.0247(4)$ \\
\hline & & & &
\end{tabular}

\section{Source of material}

Chemical materials were purchased from commercial source and used without further purification. The solvent is deionized water. IR spectra were measured on a Nicolet 170SX spectrometer in the $4000-400 \mathrm{~cm}^{-1}$ region.

The synthesis was carried out in a $20 \mathrm{~mL}$ high pressure resistant glass bottle under autogenous pressure. The reactor with a mixture of 2,3-pyridinedicarboxylic acid ( $0.5 \mathrm{mmol}$, $83.5 \mathrm{mg}), \mathrm{NaOH}$ (1 mmol, $40 \mathrm{mg})$ and $\mathrm{H}_{2} \mathrm{O}(6 \mathrm{~mL})$ was sealed and heated at $353 \mathrm{~K}$ for $30 \mathrm{~min}$. And then a solution of oxalyl dihydrazide (0.5 mmol, $59 \mathrm{mg}), \mathrm{Cd}\left(\mathrm{CH}_{3} \mathrm{COO}\right)_{2} \cdot \mathrm{H}_{2} \mathrm{O}(1 \mathrm{mmol}$, $266 \mathrm{mg})$ and $\mathrm{H}_{2} \mathrm{O}(6 \mathrm{~mL})$ was added and continuously heated at $393 \mathrm{~K}$ for $24 \mathrm{~h}$ before cooling to room temperature. The colorless crystals were collected by filtration, washed with water and ethanol and dried in air. The product yield was $48 \%$ based on Cd(II). IR ( $\left.\mathrm{cm}^{-1}, \mathrm{KBr}\right)$ : 3592(m), 3403(m), 3304(s), 3194(m), 2978(w), 1573(vs), 1467(w), 1383(vs), 1187(w), 1112(m), 832(m), 707(m), 673(m), 524(m), 504(w).

\section{Experimental details}

$\mathrm{H}$ atoms were positioned geometrically and treated as riding, with $\mathrm{C}-\mathrm{H}=0.93 \AA$ A and with $U_{\text {iso }}(\mathrm{H})=1.2 U_{\text {eq }}(\mathrm{C})$.

\section{Comment}

Coordination polymers have received considerable attention because of their magnetic behaviors, optical activities as well as catalytic and luminescent properties. Acting as polyfunctional ligand 2,3-pyridinedicarboxylates were widely studied owing to their rich coordination modes [5-10]. Most of them are six-coordinated Cd-complexes.

The structure of the complex is as shown in the Figure (symmetry operations A: $-1 / 2+x, 1 / 2-y,-1 / 2+z$; B: $1-x,-y, 1-z$; C: $1-x, 1-y, 1-z$ and $\mathrm{D}:-x$, $1-y, 1-z)$. The $\mathrm{Cd}(\mathrm{II})$ is seven coordinated by five oxygen atoms and one nitrogen atom from four deprotonated 2,3pyridinedicarboxylato ligands $\left(\mathrm{pda}^{2-}\right)(\mathrm{O} 1 \mathrm{~A}, \mathrm{O} \mathrm{A}, \mathrm{O} \mathrm{B}, \mathrm{O} \mathrm{C}$, O4, and N1), and one nitrogen atom (N2) from oxaloyl dihydrazide. The two carboxyl groups from the same $\mathrm{pda}^{2-}$ show two different types of coordination and connect $\mathrm{Cd}$ (II) centers forming a three-dimensional network. The $\mathrm{Cd}-\mathrm{O}$ and $\mathrm{Cd}-\mathrm{N}$ bond distances range from 2.2965(13) $\AA$ to 2.3836(13) $\AA$ and from $2.3313(16) \AA$ to $2.3338(16) \AA$, respectively. The data are different from those of reported [10] Cd-O $\left(\mathrm{pda}^{2-}\right)$ (2.2652 $\AA$ to $2.6319 \AA$ ) and $\mathrm{Cd}-\mathrm{N}\left(\mathrm{pda}^{2-}\right)$ (2.2912 $\AA$ ) distances, with the former obviously shorter and the latter a little longer. These phenomena can be attributed to the different coordination modes.

There are intermolecular hydrogen-bonding interactions between crystal water molecules and $\mathrm{pda}^{2-}$, oxaloyl dihydrazide and pda $^{2-}$ as well as crystal water molecules and oxaloyl dihydrazide. The D-A distances range from 2.784(2) $\AA$ to 2.999 (3) ̊.

Acknowledgements: This work was supported by Hubei Provincial Central Committee Guiding Local Science and Technology Development Project (No. 2019ZYYD074).

\section{References}

1. Bruker. APEX2, SAINT and SADABS. Bruker AXS Inc., Madison, WI, USA (2009).

2. Sheldrick, G. M.: SHELXT - integrated space-group and crystal-structure determination. Acta Crystallogr. A71 (2015) 3-8.

3. Sheldrick, G. M.: Crystal structure refinement with SHELXL. Acta Crystallogr. C71 (2015) 3-8.

4. Brandenburg, K.: DIAMOND. Visual Crystal Structure Information System. Ver. 4.0. Crystal Impact, Bonn, Germany (2015).

5. Wang, G. H.; Li, Z. G.; Jia, H. Q.; Hu, L. H.; Xu, J. W.: Metalorganic frameworks based on the pyridine-2,3-dicarboxylate and a flexible bispyridyl ligand: syntheses, structures, and photoluminescence. CrystEngComm 11 (2009) 292-297.

6. Zou, J. Z.; Xu, Z.; Chen, W.; Lo, K. M.; You, X. Z.: Synthesis, structure and magnetic properties of new polymeric compounds containing manganese (II)-Pzdc (PzdcH: 2,3Pyrazinedicarboxylic acid). Polyhedron 18 (1999) 1507-1512. 
7. Han, Z. B.; Ma, Y.; Sun, Z. G.; You, W. S.: Hydrothermal synthesis, crystal structure and photoluminescent properties of a novel 3-D coordination polymer $\left[\mathrm{Cd}_{2}(\mathrm{pydc})_{2}\left(\mathrm{H}_{2} \mathrm{O}\right)\right]_{n}$ (pydc $=$ pyridine-2,3-dicarboxylate). Inorg. Chem. Commun. 9 (2006) 844-847.

8. Barbara, B.; Maciej, H.; Agnieszka, J. W.; Joanna, M.; Wojciech, N.; Katarzyna, S.: Comparative study on Cd(II) and CA(II) model complexes with pyridine-2,3-dicarboxylic acid: synthesis, crystal structure and spectroscopic investigation. Polyhedron 29 (2010) 1191-1200.
9. Prakash, K.; Golam, M.; Ryotaro, M.; Susumu, K.; Tapas, K. M.: A pillared-bilayer porous coordination polymer with a 1D channel and a 2D interlayer space, showing unique gas and vapor sorption. Chem. Commun. 47 (2011) 8106-8108.

10. Zheng, X. X.; Li, L.; Ran, J. W.: Crystal structure catenapoly[diaqua-( $\mu_{2}$-oxalyl dihydrazide- $\left.\kappa^{4} N, O, N^{\prime}, O^{\prime}\right)$-bis ( $\mu_{2}$-pyridine-2,3-dicarboxylato- $\mathrm{K}^{3} \mathrm{~N}, \mathrm{O}, \mathrm{O}^{\prime}$ ) dicadmium(II)] hexahydrate, $\mathrm{C}_{16} \mathrm{H}_{28} \mathrm{O}_{18} \mathrm{~N}_{6} \mathrm{Cd}_{2}$. Z. Kristallogr. NCS 235 (2020) 573-574. 